\title{
WIENER \\ SLAVISTISCHES JAHRBUCH
}

Band 53 
WIENER SLAVISTISCHES JAHRBUCH

Gedruckt mit Unterstützung aus den Mitteln des Instituts für Slawistik der Universität Wien

Herausgebergremium

von Seiten der Österreichischen Akademie der Wissenschaften: Stanislaus Hafner $\uparrow$, Radoslav Katičić, Gerhard Neweklowsky

von Seiten des Instituts für Slawistik der Universität Wien: Juliane Besters-Dilger, Heinz Miklas, Stefan Michael Newerkla

\author{
Redaktion: \\ Juliane Besters-Dilger, Georg Holzer (Schriftleiter), \\ Radoslav Katičić, Heinz Miklas, Gerhard Neweklowsky, \\ Stefan Michael Newerkla, Fedor Poljakov, Stefan Simonek (Redakteur), \\ Josef Vintr, Pavol Winczer, Alois Woldan
}

Redaktionsadresse:

Institut für Slawistik

der Universität Wien

Universitätscampus AAKH, Hof 3,

Spitalgasse 2,

A-1090 Wien

Administration und technische Bearbeitung:

Sylvia Richter

Für Symposiumsbeiträge tragen ausschließlich die Autorinnen und Autoren die Verantwortung. Die Beiträge zu diesem Band wurden redigiert von Andreas Leben und Gerhard Neweklowsky.

Die verwendete Papiersorte ist aus chlorfrei gebleichtem Zellstoff hergestellt, frei von säurebildenden Bestandteilen und alterungsbeständig.

Copyright (C 2007 by Österreichische Akademie der Wissenschaften Wien

Alle Rechte vorbehalten

Druck: Börsedruck Ges.m.b.H., A-1230 Wien

ISBN 978-3-7001-3959-1

ISSN 0084-0041

http://hw.oeaw.ac.at/3959-1

http://verlag.oeaw.ac.at 